\title{
Brazilian Loneliness Scale: Evidence of Validity Based on Relations to Depression, Anxiety and Stress
}

\author{
Sabrina Martins Barroso ${ }^{1}$ \\ Heloisa Gonçalves Ferreira ${ }^{2}$ \\ Felipe Costa Aranjo ${ }^{3}$ \\ ${ }^{1}$ Federal University of Triângulo Mineiro, Uberaba, Minas Gerais, Brasil \\ ${ }^{2}$ Universidade do Estado do Rio de Janeiro (UERJ), Rio de Janeiro, Brasil \\ ${ }^{3}$ University of São Paulo, Ribeirão Preto, São Paulo, Brasil
}

\begin{abstract}
This paper aimed mainly to investigate the relationships between Brazilian Loneliness Scale (UCLA-BR) and the levels of depression, anxiety and stress in Brazilian college students. These concepts were assessed using validated scales (Patient Health Questionnaire - PHQ-9, Depression, Anxiety and Stress Scale - DASS-21, Beck Anxiety Inventory - BAI and Lipp Stress Symptom Inventory - ISSL). A total of 325 college students participated and responded all the instruments. Descriptive, correlational and group differences analyzes were conducted. The prevalence of depression, anxiety and stress varied depending on the instrument used. UCLA-BR presented evidence of validity based on relationships with depression, anxiety and stress, especially depression (assessed by DASS-21). Analysis of measurement scales can help to understand aspects of college students' mental health.

Keywords: testing; depression; anxiety; stress; college students.
\end{abstract}

Escala Brasileira de Solidão: Evidência de Validade Baseada na Relação Entre Depressão, Ansiedade e Estresse

\begin{abstract}
Resumo
Esse trabalho teve por objetivo principal investigar as relações existentes entre a Escala Brasileira de Solidão (UCLA-BR) e os níveis de depressão, ansiedade e estresse em estudantes universitários brasileiros. Esses conceitos foram avaliados utilizando escalas validadas (Questionário sobre a saúde do paciente - PHQ-9, Depression, Anxiety and Stress Scale - DASS-21, Inventário Beck de Ansiedade - BAI e Inventário de Sintomas de Stress de Lipp - ISSL). Participaram 325 universitários, que responderam todos os instrumentos. Foram conduzidas análises descritivas, correlacionais e de diferenças de grupo. A prevalência de depressão, ansiedade e estresse variou dependendo do instrumento utilizado. A UCLA-BR apresentou evidências de validade baseadas nas relações com depressão, ansiedade e estresse, principalmente depressão (avaliada pela DASS-21). Analisar as escalas de medida pode ajudar a compreender aspectos da saúde mental dos universitários.

Palavras-chave: escalas, depressão, ansiedade, estresse, estudantes universitários.
\end{abstract}

Escala Brasileña de Soledad: Evidencia de Validez Baseada en la Relación Entre Depression, Ansiedad y Estrés

\begin{abstract}
Resumen
Este estudio tuvo como objetivo principal investigar la relación entre la Escala Brasileña de Soledad (UCLA-BR) y los niveles de depresión, ansiedad y estrés en estudiantes universitarios brasileños. Estos conceptos se evaluaron mediante escalas validadas (Cuestionario de Salud del Paciente - PHQ-9, Escala de Depresión, Ansiedad y Estrés - DASS-21, Inventario de Ansiedad de Beck - BAI e Inventario de Síntomas de Estrés de Lipp - ISSL). Participaron 325 estudiantes, quienes respondieron a todos los instrumentos. Se realizaron análisis descriptivos, correlacionales y de diferencias grupales. La prevalencia de depresión, ansiedad y estrés varió de acuerdo con el instrumento utilizado. UCLA-BR presentó evidencias de validez basadas en relaciones con depresión, ansiedad y estrés, especialmente depresión (evaluado por DASS-21). El análisis de escalas de medición puede ayudar a comprender aspectos de la salud mental de los estudiantes universitarios.

Palabras clave: escalas; depresión; ansiedad; estrés; estudiantes universitarios.
\end{abstract}

\section{Introduction}

Psychological assessment of emotional states using psychometric instruments is a frequent practice for Psychologists. However, choosing the appropriate instrument might lead to some issues regarding its psychometric properties and suitability for specific populations. In Brazil, screening and diagnostic scales are widely used to assess depression and anxiety disorders in college students (Serra, Dinato, \& Caseiro, 2015; Fernandes, Vieira, Silva, Avelino, \& Santos, 2018). These disorders are quite frequent in college students who seek psychological and psychiatric support (Pinho, 2016; Campos, Oliveira, Mello, \& Dantas, 2017). The estimated prevalence for depression in Brazilian college students might reach 30\% (Serra et al. 2015; Leandro, 
Gomes, Ferreira, \& Cavalcanti, 2018), while anxiety prevalence can reach $60 \%$ in this population (Fernandes et al., 2018).

Stress is less assessed in Brazilian college students in epidemiological studies when compared to depression and anxiety. However, some investigations showed that stress symptoms are also very common in this population (Furtado, Falcone, \& Clark, 2003; Neto, Silva, \& Oliveira, 2017), indicating that about $72 \%$ of college students had experienced some level of stress (Assis, Lopes, Silva, \& Santini, 2013).

Loneliness is another construct very important to be explored in college students, since there is evidence of high rates and increasing trends of loneliness among students at the university (Hysing, Petrie, Bøe, Lønning, \& Sivertsen, 2020). Loneliness seems to significantly affect people's mental health, given it predicts depression (Barroso, Baptista, \& Zanon, 2018) and it is also a risk factor for suicide in general population (Stickley \& Koyanagi, 2016).

There is no consensual definition of loneliness, but one of the most accepted definition among researchers assumes that loneliness comprises both a cognitive and emotional factor (Hawkley \& Cacioppo, 2010; Barroso, Andrade, Midgett, \& Carvalho, 2016). According to this model, loneliness is a cognitive perception that social relationships are insufficient or inadequate, which in turn generates emotional reactions of sadness and emptiness. Loneliness does not depend on being objectively alone. Since there are no negative feelings associated with being alone, such condition does not represent loneliness. On the other hand, even when surrounded by people, one can feel lonely (Hawkley \& Cacioppo, 2010).

In Brazil we still have few studies investigating the prevalence of loneliness in college students (Barroso, Oliveira, \& Andrade, 2019; Oliveira \& Barroso, 2020), because only recently an adapted measure to access loneliness (UCLA-BR) was available to be used in Brazil (Barroso et al., 2016). The UCLA-BR is an instrument adapted from the UCLA Loneliness Scale (Russell, Peplau, \& Ferguson, 1978; Russell, Peplau, \& Cutrona, 1980), which is a gold standard tool widely accepted and used for loneliness assessment in many populations (Lee et al., 2018), including college students (Zhang et al., 2018). The Brazilian version of this instrument showed good psychometric properties, including evidence of validity based on test content, consequences of testing, internal structure and relations to other variables (Barroso et al., 2016). Evidence of validity based on relations to other variables was demonstrated by significant relations between loneliness and depression, using the Patient Health Questionnaire - PHQ-9 (Barroso et al., 2016; Santos et al., 2013). However, relations between UCLA-BR and other screening scales commonly used in Brazil to assess college students' mental health, such as anxiety and stress scales, were not yet investigated.

The Beck Anxiety Inventory - BAI (Cunha, 2001) is a scale frequently used in Brazilian epidemiological studies to investigate the prevalence of anxiety in college students (Serra et al., 2015; Leão et al., 2018). Also, the Lipp Stress Symptoms Inventory for Adults - ISSL (Lipp \& Guevara, 1994; Lipp, 2000) is an instrument traditionally used to evaluate the level of stress in Brazilian adults, including college students (Furtado, Falcone, \& Clark, 2003; Pellegrini, Calais, \& Salgado, 2012; Assis et al., 2013).

Based on the assumption that symptoms of depression, anxiety and stress might overlap (such as negative affect, emotional distress and physiological reactions), a scale that simultaneously assess depression, anxiety and stress in adults was developed, namely the Depression, Anxiety and Stress Scale - DASS-21 (Brown, Chorpita, Korotitsch, \& Barlow, 1997). This instrument has recently been adapted and validated to the Brazilian context (Vignola \& Tucci, 2014) and it was applied in college students to evaluate their mental health state (Borges, Figueiredo, \& Souto, 2017). This instrument has the advantage of assessing three constructs simultaneously, in addition to presenting faster and easier application.

Therefore, it is possible to notice a great variety of valid instruments to assess mental health state, including depression, stress and anxiety. However, the relationships between these constructs and loneliness have not yet been further investigated in Brazil, especially in college students. Investigating the relationships between these constructs is relevant to better understand the mental health profile of this population and the role of loneliness for mental health. Besides, studies of this nature make possible to deeply investigate the psychometric properties of the instruments commonly used to assess mental health constructs, which might bring some support to professionals and researchers to make better decisions regarding the use and application of screening scales in the context of psychological assessment of college students.

Therefore, this paper aimed mainly to investigate evidence of validity of UCLA-BR based on relations to 
other variables, by exploring the relationships between UCLA-BR with specific measures of depression (PHQ-9 and DASS-21), anxiety (BAI and DASS-21) and stress (ISSL and DASS-21) in Brazilian college students. The prevalence of loneliness, depression, anxiety and stress were also investigated, as well as the associations between the classification levels of depression, anxiety and stress assessed by the instruments.

\section{Method}

Cross-sectional and correlational study to investigate the psychometric properties of UCLA-BR.

\section{Participants}

A total of 325 college students from Minas Gerais state participated in the study. The participants' average age was 22.18 with a standard deviation of 3.78 . The majority of students was women $(73.50 \%)$ and single (94.50\%). Participants were invited through online social networks and responded to the instruments online, after agreeing to the Online Free and Informed Consent Form.

\section{Instruments}

The Brazilian Loneliness Scale - UCLA-BR - the instrument was adapted from the foreign version UCLA-R (Russel, Peplau, \& Cutrona, 1980), and validated for Brazil by Barroso et al. (2016). UCLABR presented an excellent internal consistency $(\alpha=$ $0.94)$ and significant relationships with depression and social support, indicating evidence of external validity (Barroso et al., 2016). This instrument assesses the level of loneliness through 20 items that must be answered using a four point Likert scale that varies from Never (0) to Frequently (3). Scores may indicate levels of loneliness from minimal (0-22 points), low (23-35 points), moderate (36-47 points) and severe (48-60 points).

DASS-21 is an instrument created by Brown et al. (1997) and validated for Brazil by Vignólia and Tucci (2014). It comprises three subscales with seven items each, to assess symptoms of depression $(\alpha=0,92)$, anxiety $(\alpha=0.86)$ and stress $(\alpha=0.90)$, with a four point Likert scale (ranging from 0 to 3 points). The instrument showed strong and significant correlations with other scales that assessed depression (Beck Depression Inventory), anxiety (BAI) and stress (ISSL). Scores are obtained by the sum of the responses of each subscale and levels of depression, anxiety and stress are classified as normal, mild, moderate, severe and extremely severe (Vignola \& Tuci, 2014).

PHQ-9 is an instrument validated for Brazil by Santos et al. (2013) to assesses depressive symptoms through nine questions. Responses are presented on a Likert scale ranging from zero (not at all) to three (nearly every day). Scores up to nine points indicate negative screening for depression and scores higher than nine points indicate positive screening for depression, which is classified as mild (10-14 points), moderate (15 and 19 points) and severe (20-27 points). The scale had a significant strong correlation with the Composite International Diagnostic Interview (CIDI) (Osório, Mendes, Crippa, \& Loureiro, 2009), showing $77.5 \%$ of sensitivity and $86.7 \%$ of specificity (Santos et al., 2013).

BAI is an instrument validated for Brazil by Cunha (2001) to evaluate symptoms of anxiety through 21 items. Scores range from 0 to 63 and anxiety is classified as minimal (0-10 points), low (11-19 points), moderate (20-30 points) and severe (31-63 points). BAI showed significant relationships with depression (accessed by BDI) in psychiatric, clinical and non-clinical samples, with Cronbach's alpha between 0.83 and 0.92 (Cunha, 2001).

ISSL is an instrument validated for Brazil by Lipp and Guevara (1994) to investigate the stages of stress (alertness, resistance, near-exhaustion and exhaustion) during three distinct periods (24 hours, one week and one month) (Lipp, 2000). This instrument was associated with clinical diagnosis of stress performed by specialists (Lipp \& Guevara, 1994).

Table 1 displays the internal consistency of the instruments used in the study, measured by Cronbach's alpha. It is possible to notice that all instruments had excellent internal consistency in the sample used in this study, ranging from 0.89 to 0.95 .

Table 1.

Internal Consistency (Cronbach's Alpha) of Loneliness, Depression, Anxiety and Stress Scales $(N=325)$

\begin{tabular}{cc}
\hline Scales & Internal Consistency \\
\hline UCLA-BR & 0,95 \\
PHQ-9 & 0,89 \\
BAI & 0,93 \\
ISSL & 0,91 \\
DASS-21 & 0,94 \\
\hline
\end{tabular}


Analysis

Descriptive analysis was performed (average scores, standard deviations and classification of the participants in each instrument). The associations between the classifications for depression, anxiety and stress assessed by the instruments were investigated using Chi-square tests. The Kolmogorov-Smirnov normality test was applied to check the distribution of the quantitative variables and the analysis showed nonnormal distributions (KS from 0.07 to $0.17, \mathrm{p}<0.001$ ). Spearman correlations were used to investigate relations between UCLA-BR with measures of depression, anxiety and stress.

\section{Ethical aspects}

This research followed the ethical principles of the norms 466/12 and 510/16 of the Brazilian Health Council (Conselho Nacional de Saúde). The project was approved by the Research Ethics Committee (CAAE 85839418.8.1001.5150), and all the participants agreed with their explicit consent before having access to the instruments on Survey Monkey online platform.

\section{Results}

Table 2 presents the descriptive analysis of each scale. It can be noticed that $20.7 \%$ of the sample suffers from moderate to severe loneliness.

When deeply investigating the instruments that assessed the same constructs, it was observed a variation in the classification levels for depression, anxiety and stress. For depression, PHQ-9 identified $37.2 \%$ of the sample suffering from moderate to severe depression, with $40.9 \%$ of the cases without any symptom of depression. For the same construct, DASS-21 screened $43.8 \%$ of cases suffering from moderate to extremely severe depression and $38.8 \%$ of the cases without a depressive symptomatology. The proportions of people who screened for moderate to severe depression using PHQ-9 and DASS-21 were significant statically different $\left(\chi^{2}=52,98 ; \mathrm{p}<0,001\right)$.

BAI screened $53.2 \%$ of the sample with minimal to mild anxiety and $20.6 \%$ with severe symptoms. On the other hand, DASS-21 identified that $55.7 \%$ of the sample had normal anxiety symptomatology and $19.70 \%$ showed severe or extremely severe symptoms of anxiety. The proportions of people with severe anxiety symptoms screened by BAI and DASS-21 were significant statically different $\left(\chi^{2}=110,17 ; \mathrm{p}<\right.$ $0,001)$.
For stress assessment, a greater variation among the instruments was observed. ISSL identified 21.5\% of the sample without stress symptoms and $37.5 \%$ was in the most severe stage of stress (exhaustion stage). When stress was assessed by DASS-21, $48.3 \%$ of the participants showed no stress symptom and 20.6\% reported from severe to extremely severe symptoms. The proportions of people with severe stress symptoms screened by ISSL and DASS-21 were significant statically different $\left(\chi^{2}=107,79 ; \mathrm{p}<0,001\right)$.

Table 3 summarizes the associations between the instruments classifications that assessed the same constructs, namely: (i) depression, assessed by PHQ9 and DASS-21; (ii) anxiety, assessed by BAI and DASS-21; and (iii) stress, assessed by ISSL and DASS-21. The associations between the instruments' classifications were statistically significant, using both chi-square and correlational analysis. Considering the instruments mentioned previously, it was also observed that the relationships between the classifications for depression, anxiety and stress showed moderate correlations.

The relationships between UCLA-BR and depression (PHQ-9 and DASS-21), anxiety (BAI and DASS-21) and stress (ISSL and DASS-21) can be seen in Table 4. Considering only the relationships between total scores of the instruments, it was observed that they are positive and significant, indicating that the greater de loneliness, the greater the anxiety, depression and stress experienced by students. UCLA-BR and DASS-21 showed the strongest correlations, especially with the depression subscale (rho $=0.64, \mathrm{p}<0.001$ ), while the weaker correlation was observed between UCLA-BR and BAI (rho $=0.35, \mathrm{p}<0.001$ ).

Taking into account the associations between levels of loneliness measured by UCLA-BR and other instruments, the strongest relations were observed between minimal loneliness and depression (rho = $0.55, \mathrm{p}<0.001$ ), and minimal loneliness and stress (rho $=0.40, \mathrm{p}<0.001)$, when depression and stress were measured by DASS-21. It was also possible to notice that all the relationships between minimal loneliness and other scales were negative and significant, indicating that the greater the minimal level of loneliness, the lower the degree of anxiety, depression and stress experienced by the participants.

\section{Discussion}

This paper mainly investigated the relationships between UCLA-BR with specific measures of 
Table 2.

Prevalence of Loneliness, Depression, Anxiety and Stress $(N=325)$

\begin{tabular}{|c|c|c|c|}
\hline Variable & $\mathrm{n}$ & $\%$ & (DP) \\
\hline Loneliness - UCLA-BR & & & $22.60(14.48)$ \\
\hline Minimal & 171 & 52.6 & \\
\hline Low & 87 & 26.8 & \\
\hline Moderate & 47 & 14.5 & \\
\hline Severe & 20 & 6.2 & \\
\hline Depression - PHQ-9 & & & $12.16(6.78)$ \\
\hline Absence & 133 & 40.9 & \\
\hline Low & 71 & 21.8 & \\
\hline Moderate & 70 & 21.5 & \\
\hline Severe & 51 & 15.7 & \\
\hline Depression - DASS-21 & & & $6.92(5.43)$ \\
\hline Normal & 126 & 38.8 & \\
\hline Low & 57 & 17.5 & \\
\hline Moderate & 59 & 18.2 & \\
\hline Severe & 35 & 10.8 & \\
\hline Extremely Severe & 48 & 14.8 & \\
\hline Anxiety - BAI & & & $19.59(12.40)$ \\
\hline Minimal & 96 & 29.5 & \\
\hline Low & 77 & 23.7 & \\
\hline Moderate & 85 & 26.2 & \\
\hline Severe & 67 & 20.6 & \\
\hline Anxiety - DASS-21 & & & $4.18(4.31)$ \\
\hline Normal & 181 & 55.7 & \\
\hline Low & 24 & 7.4 & \\
\hline Moderate & 56 & 17.2 & \\
\hline Severe & 23 & 7.1 & \\
\hline Extremely Severe & 41 & 12.6 & \\
\hline \multicolumn{4}{|l|}{ Stress - ISSL } \\
\hline Absence & 70 & 21.5 & \\
\hline Resistance Stage & 130 & 40.0 & \\
\hline Near-exhaustion Stage & 03 & 0.09 & \\
\hline Exhaustion Stage & 122 & 37.5 & \\
\hline Stress - DASS-21 & & & $8.21(5.17)$ \\
\hline Normal & 157 & 48.3 & \\
\hline Low & 38 & 11.7 & \\
\hline Moderate & 63 & 19.4 & \\
\hline Severe & 42 & 12.9 & \\
\hline Extremely Severe & 25 & 7.7 & \\
\hline
\end{tabular}


Table 3.

Associations between the Classification Levels of Depression, Anxiety and Stress Assessed by the Instruments $(N=325)$

\begin{tabular}{|c|c|c|c|c|c|c|c|}
\hline & & & DASS-21 & & & & \\
\hline & Normal & Low & Moderate & Severe & $\begin{array}{c}\text { Extremely } \\
\text { Severe }\end{array}$ & $\chi^{2}$ & rho \\
\hline PHQ-9 & & & & & & $155.72^{* *}$ & $0.59 *$ \\
\hline Absence & 83 & 27 & 16 & 06 & 01 & & \\
\hline Low & 26 & 14 & 17 & 09 & 05 & & \\
\hline Moderate & 17 & 13 & 16 & 13 & 11 & & \\
\hline Severe & 00 & 03 & 10 & 07 & 31 & & \\
\hline BAI & & & & & & $110.17 * *$ & $0.47 *$ \\
\hline Minimal & 84 & 06 & 06 & 00 & 00 & & \\
\hline Low & 40 & 10 & 19 & 06 & 02 & & \\
\hline Moderate & 35 & 03 & 20 & 13 & 14 & & \\
\hline Severe & 22 & 24 & 56 & 23 & 41 & & \\
\hline ISSL & & & & & & $107.79 * *$ & $0.55^{*}$ \\
\hline Absence & 62 & 04 & 02 & 02 & 00 & & \\
\hline Resistance Stage & 71 & 19 & 23 & 14 & 03 & & \\
\hline Near-exhaustion Stage & 01 & 00 & 01 & 01 & 00 & & \\
\hline Exhaustion Stage & 23 & 15 & 37 & 25 & 22 & & \\
\hline
\end{tabular}

${ }^{* *} \mathrm{p}<0,001 ; * \mathrm{p} \leq 0,05$

Table 4.

Spearman Correlations between UCLA-BR with PHQ-9 BAI ISSL and DASS-21

\begin{tabular}{lccccc}
\hline \multicolumn{7}{c}{ UCLA-BR } \\
\hline PHQ-9 & Total Score & Minimal & Low & Moderate & Severe \\
\hline BAI & $0.48^{* *}$ & $-0.38^{* *}$ & $0.15^{* *}$ & $0.19^{* *}$ & $0.24^{* *}$ \\
ISSL: stress classification & $0.35^{* *}$ & $-0.25^{* *}$ & 0.10 & $0.13^{*}$ & $0.15^{* *}$ \\
DASS-21: depression & $0.49^{* *}$ & $-0.37^{* *}$ & 0.07 & $0.29^{* *}$ & $0.21^{* *}$ \\
DASS-21: anxiety & $0.64^{* *}$ & $-0.55^{* *}$ & $0.21^{* *}$ & $0.33^{* *}$ & $0.26^{* *}$ \\
DASS-21: stress & $0.47^{* *}$ & $-0.38^{* *}$ & $0.16^{* *}$ & $0.19^{* *}$ & $0.23^{* *}$ \\
\hline
\end{tabular}

** $\mathrm{p}<0,001 ; * \mathrm{p}<0,05$

depression (PHQ-9 and DASS-21), anxiety (BAI and DASS-21) and stress (ISSL and DASS-21) in Brazilian college students. The prevalence of loneliness, depression, anxiety and stress assessed by these instruments were also investigated. The average level of loneliness for Brazilian college students was 22.6 points, indicating that more than a half of the participants $(52.60 \%)$ had minimal level of loneliness. When considering moderate to severe levels of each construct, the results showed that prevalence ranged from $37.2 \%$ to $43.8 \%$ 
for depression, $36.9 \%$ to $46.8 \%$ for anxiety, and 40.0 to $77.6 \%$ for stress, depending on the instrument used.

Regarding the prevalence of loneliness, the results of this sample showed a higher proportion of students with severe loneliness when compared to previous studies with Brazilian college students using UCLA-BR, that found a proportion of 2,4\% college students with severe loneliness (Barroso et al., 2019) and a proportion of $2,1 \%$ psychology students with severe loneliness (Oliveira \& Barroso, 2020). In addition, Barroso et al. (2019) found higher levels of loneliness in students from the field of humanities, who were entering the university and who were female.

However, when compared to international findings, Brazilian students showed lower levels of loneliness. For example, a study performed with Chinese college students showed that the average of loneliness, measured by the Chinese version of UCLA, was 39.48 points (Zhang, 2018), indicating a higher average of loneliness when compared to the Brazilian sample. Another study (Chang, 2018) investigated gender differences in the prevalence of loneliness in 168 African American college students by applying UCLA, and revealed even higher average scores for both men (42.65 points) and women (43.25 points), when compared to the Brazilian sample. Although many variables might influence loneliness levels in college students, such as sociodemographic characteristics (Chang, 2018), these findings may suggest that loneliness might also be dependent on cultural factors. The results of this study suggest that Brazilian college students might suffer less of loneliness, when compared to American and Chinese students, but further investigation still need to be done in order to better understand the influence of cultural factors in the manifestation of loneliness in college students.

A Brazilian study (Barros et al., 2017) that also used PHQ-9 to assess depression in 49,025 adults found that only $9.7 \%$ of adults showed any depression symptoms, a much lower percentage when compared to the proportion found in the present study, where $37.2 \%$ suffered from moderate to severe depression, when PHPQ-9 was applied. Although there is no other available study using PHQ-9 to assess depression in Brazilian college students, it is possible to infer that the proportion of college students with depression symptoms is higher than adults in general. College students might be more likely to be depressed when compared to the general adult population due to the circumstances they need to face when entering to the university: leaving their parents' home, adapting to a new environment, dealing with new life challenges, the need of establishing new ties, which might lead to depression symptoms in this specific stage of their lives.

Through the analysis of DASS-21, it was indicated that $43.8 \%$ of the Brazilian college students had moderate to extremely severe depression. This result was quite similar to other Brazilian study that used the same measure (Borges et al., 2017), which investigated depression levels in 200 college students from the state of Ceará and identified a proportion of $42.5 \%$ of the sample with moderate to extremely severe depression. It is important to highlight that both studies used samples from different Brazilian states, indicating that the university context might generate similar psychological demands regarding depression that may not be dependent on Brazilian regional aspects, or maybe DASS-21 is not influenced by regional variations in its discriminative capacity to assess depression.

Regarding anxiety, BAI identified a proportion of $46.8 \%$ of college students with moderate to severe anxiety. This proportion is much higher than the prevalence found in other investigations using the same instrument with nursing students (32.7\%) (Fernandes et al., 2018), medical students (5.6\%) (Serra et al., 2015) and students from health sciences (37.8\%) (Leão et al., 2018). When assessing anxiety using DASS-21, 36.9\% of the cases in this study showed moderate to extremely severe anxiety, a higher proportion compared to the sample of college students from Ceará, where $29.5 \%$ of the cases was diagnosed with moderate to extremely severe anxiety, by using the same instrument (Borges et al., 2017). Despite the regional influences that might have contributed to such variation, it is also possible that the field of the study plays a role in influencing college students' mental health. Some studies indicate that students from health sciences are more likely to experience emotional problems, although there is still little investigation about this issue (Campos et al., 2017). The sample of the present study was composed by students from different fields, however, we did not control the effects of these variables in the present analysis.

When using ISSL to evaluate stress, $78.5 \%$ of the sample was diagnosed with stress at some level, a similar proportion found in Psychology students from the North region of Brazil (72\%) using the same instrument (Assis et al ., 2013). When using DASS-21to assess the same construct in this study, it was found that a smaller percentage of the sample $(51.7 \%)$ presented stress at some level. Considering only students 
who were diagnosed with moderate to extremely severe stress when using DASS-21, the prevalence found in this study was $40 \%$, which is a much higher than the prevalence found in students from Ceará state $(7 \%)$ using the same measure (Borges et al., 2017). The factors associated to the manifestation of mental disorders in college students were not investigated in this paper, so it is not possible to indicate the reasons for variations in the stress prevalence, however, it is clear that ISSL and DASS-21 have different sensitivities and further investigation needs to be done in order to verify which measure has better discriminative properties. Future studies should also address issues regarding the influence of Brazilian regional aspects in college students' mental health.

When we compare the proportions of individuals diagnosed with some mental disorder considering only the findings of this study, it is possible to notice similar variations in the proportions of participants diagnosed with anxiety and stress. When assessing anxiety and stress, DASS-21 tended to screen fewer positive cases when compared to other instruments. These findings demonstrate the need to investigate the sensitivity and specificity of these instruments for different samples, which may help clinicians and researchers to make a better use of these instruments.

It is important to notice that studies about the psychometric properties of DASS-21 (Vignólia \& Tucci, 2014) are more updated than the available data about the psychometric properties of BAI (Cunha, 2001) and ISSL (Lipp \& Guevara, 1994; Lipp, 2000). These last studies are dated from more than 15 years ago, which is beyond the maximum time recommended by the Brazilian Council of Psychology (CFP) for reviewing the psychometric data of the instruments, including norms and cut-off points (CFP, 2018). In this study, ISSL and BAI presented excellent internal consistency as well as significant associations with the classification levels of mental disorders assessed by the other measures. However, we recommend that studies to investigate the specificity and sensitivity of these instruments should be performed, as well as studies to review their psychometric properties and to update the norms of the instruments.

When depression was assessed, similar proportions of individuals with at least some level of depression were observed using PHQ-9 (59.1\%) and DASS-21 (61.2\%). Both instruments brings updated data about their psychometric properties (Santos et al., 2013; Vignólia \& Tucci, 2014), which may have contributed for these similar outcomes. Moreover, the proportion of individuals diagnosed with depression was similar to another study with Brazilian college students that used DASS-21 (Borges et al., 2017), which can also suggest that depression in college students may not be dependent on regional influences in Brazil.

\section{Relationship between loneliness with measures of depression, anxiety and stress}

Through the analysis of the relationships between loneliness (measured by UCLA-BR) with depression (PHQ-9 and DASS-21), anxiety (BAI and DASS-21) and stress (ISSL and DASS-21), it was observed significant relationships among all these constructs. These findings suggested that, in the Brazilian context, the higher the loneliness experienced by college students, the higher the levels of depression, anxiety and stress. These findings also bring further evidence of UCLABR' validity based on relations to other variables, since the relationship between loneliness and depression in adults and college students has been well documented in the international literature (Victor \& Yang, 2012; Daniel, 2013; Chang, 2018), and in the Brazilian context (Barroso et al., 2016; Barroso et al., 2019; Oliveira \& Barroso, 2020). In the same way, relationships between loneliness and anxiety (Caplan, 2007; Chang, 2018), and between loneliness and stress (Stoliker \& Lafreniere, 2015; Segrin, McNelis \& Pavlich, 2017) have also been documented in the international literature.

By analyzing the relationships between UCLA-BR with each instrument separately (DASS-21, PHQ-9, BAI and ISSL), it was possible to notice that the strongest association was found between UCLA-BR and DASS-21, especially with DASS-21 depression scale. In fact, other studies have also identified stronger correlations between loneliness and depression (Barroso et al., 2016; Chang, 2018), when compared to the associations found between loneliness and anxiety (Chang, 2018) and between loneliness and stress (Segrin et al., 2017). By examining the relationship between loneliness and depression in college students, Barroso et al. (2016) found a significant positive correlation of 0.59, while Chang (2018) identified a significant positive correlation of 0.68 between these same constructs. On the other hand, Chang (2018) identified a correlation of 0.51 between loneliness and anxiety, and Segrin et al. (2017) found even a weaker correlation of 0.23 between loneliness and stress. These findings suggest that loneliness is more associated to depression than anxiety or stress, probably because some symptoms of 
depression and loneliness might overlap, such as sadness, social isolation, dismay and emotional blunting.

Despite the significant relationships found between total scores of UCLA-BR and BAI, and total scores of UCLA-BR and ISSL, we did not observed significant relations between all levels of loneliness established by UCLA-BR with all levels of anxiety and stress established by BAI and ISSL, respectively. Low level of loneliness had no significant relation with either BAI or ISSL. It was also observed that relations between moderate level of loneliness with BAI scores had a lower level of significance when compared to the other relations found between UCLA-BR with the other instruments. These findings may indicate that scores obtained by DASS-21 in the anxiety and stress subscales have better discriminative capacity (greater evidence of external validity) than BAI and ISSL, given the significant relationships found between UCLABR with all levels of anxiety and stress measured by DASS-21. Probably, the items of BAI and ISSL need to be updated in order to improve their sensitivity and specificity.

It is important mentioning some limitations of the present research. Despite the cross-sectional nature of the study, variables that might be associated with the constructs of interest, such as sociodemographic variables, students' fields of study and regional influences were not considered for the analysis in this paper. In addition, data collection was performed using online questionnaires. Even with a verification of the correspondence between online and face-to-face application in a pilot study with 20 people $\left(\chi^{2}=82.15 ; \mathrm{p}=0.982\right)$ prior to the larger data collection, there is always the possibility that online data collection have influenced in some degree the results.

\section{Final considerations}

This paper aimed to investigate the relationships between UCLA-BR and measures of depression, anxiety and stress in Brazilian college students. The prevalence of the constructs were analyzed and it was possible to investigate the associations between the classification levels of the constructs assessed by the instruments. In addition, UCLA-BR presented additional evidence of external validity, given the significant associations found between UCLA-BR with depression, anxiety and stress measures.

By further investigating the relationships between the instruments (UCLA-BR, DASS-21, PHQ-9, BAI and ISSL), findings of the present study suggested that UCLA-BR is more strongly associated with DASS-21, which lead us to infer that the combined use of UCLABR and DASS-21 is an easier, faster and more reliable option to be considered in order to assess the mental health state of Brazilian college students. The concomitant analysis of different instruments evaluating the same constructs indicated significant relationships between all scales investigated. Nonetheless, the analysis also showed the need of reviewing and updating the psychometric properties of scales commonly used in the Brazilian context to screen anxiety and stress, through studies to investigate their psychometric properties including their sensitivity and specificity.

Further investigations about loneliness using UCLA-BR in the Brazilian population are still needed. For example, it would be relevant to explore gender and course differences among college students regarding loneliness. Comparing loneliness in samples of college students and non-college students would also be important in order to better understand how loneliness occurs in different contexts for distinct groups.

\section{References}

Assis, C. L., Silva, A. P. F., Lopes, M. S., Silva, P. C. B., \& Santini, T. O. (2013). Stress symptoms in psychology undergraduate students from a private college in northern Brazil. Mudanças - Psicologia da Saúde, 21(1), 23-28. doi: 10.15603/2176-1019/mud. v21n $1 \mathrm{p} 23-28$

Barros, M.B.A., Lima, M.G., Azevedo, R.S.C., Medina, L.B.P., Lopes, C.S., Menezes, P.R., \& Malta, D.C. (2017). Depression and health behaviors in Brazilian adults - PNS 2013. Revista de Saúde Pública, 51, 1-8. doi: 10.1590/S1518-8787.2017051000084

Barroso, S. M., Andrade, V. S., Midgett, A. H., \& Carvalho, R. G. N. (2016). Evidence of validity of Brazilian UCLA Loneliness Scale. Jornal Brasileiro de Psiquiatria, 65(1), 68-75. doi: 10.1590/0047-2085000000105

Barroso, S. M., Baptista, M. N., \& Zanon, C. (2018). Loneliness as a predictive variable in adult depression. Estudos Interdisciplinares em Psicologia, 9(3), 26-37. doi: 10.5433/2236-6407.2018v9n3suplp26

Barroso, S. M., Oliveira, N. R., \& Andrade, V. S. (2019). Loneliness and depression: relations with personal characteristics and life habits in university 
students. Psicologia: Teoria e Pesquisa, 35, e35427. doi: 10.1590/0102.3772e 35427

Borges, K. M., Figueiredo, F. W. S., \& Souto, R. P. (2017). Night eating syndrome and emotional states in university students. Journal of Human Growth and Development, 27(3), 132-139. doi: 10.7322/jhgd.141277

Brandão,A.S.,Bolsoni-Silva,A.T.,\&Loureiro,S.R.(2017). The predictors of graduation: social skills, mental health, academic characteristics. Paidéia, 27(66), 117-125. doi: 10.1590/1982-43272766201714

Brown, T. A., Chorpita, B. F., Korotitsch, W., \& Barlow, D. H. (1997). Psychometric properties of the Depression Anxiety Stress Scales (DASS) in clinical samples. Behaviour Research and Therapy, 35(1), 7989. doi: 10.1016/s0005-7967(96)00068-x

Campos, C. R. F., Oliveira, M. L. C., Mello, T. M. V. F., \& Dantas, C. R. (2017). Academic performance of students who underwent psychiatric treatment at the students' mental health service of a Brazilian university. São Paulo Medical Journal, 135(1), 23-28. doi: 10.1590/1516-3180.2016.017210092016

Caplan, S. E. (2007). Relations among loneliness, social anxiety and problematic internet use. Cyber Psychology \& Behavior, 10(2), 234-242. doi: 10.1089/ cpb.2006.9963

Chang, E. C. (2018). Relationship between loneliness and symptoms of anxiety and depression in African American men and women: Evidence for gender as a moderator. Personality and Individual Differences, 120, 138-143. doi: 10.1016/j.paid.2017.08.035

Conselho Federal de Psicologia (2018). Resolução No 9 de 25 de Abril de 2018. Recuperado em 22 de Janeiro de 2019 de http:/ / satepsi.cfp.org.br/docs/ Resolu\%C3\%A7\%C3\%A3o-CFP-n\%C2\%BA-092018-com-anexo.pdf

Cunha, J. A. (2001). Manual da versão em português das Escalas Beck. São Paulo: Casa do Psicólogo.

Daniel, K. (2013). Loneliness and depression among college students in Kenya. Global Journal of Human Social Science Arts \& Humanities, 13(4), 10-18.

Fernandes, M. A., Vieira, F. E. R., Silva, J. S., Avelino, F. V. S. D., \& Santos, J. D. M. (2018). Prevalence of anxious and depressive symptoms in college students of a public institution. Revista Brasileira de Enfermagem, 7(1), 2298-22304. doi: 10.1590/0034-7167-2017-0752
Furtado, E. S., Falcone, E. M. O., \& Clark, C. (2003). Evaluation of stress and social skills in the academic experience of medical students of a Rio de Janeiro university. Interação em Psicologia, 7(2), 43-51. doi: $10.5380 /$ psi.v7i2.3222

Hawkley, L. C., \& Cacioppo, J. T. (2010). Loneliness matters: A theoretical and empirical review of consequences and mechanisms. Annals of Behavioral Medicine, 40(2), 1-14. doi:10.1007/ s12160-010-9210-8.

Hysing, M., Petrie, K. J., Bøe, T., Lønning, K. J., \& Sivertsen, B. (2020). Only the lonely: A study of loneliness among university students in Norway. Clinical Psychology in Europe, 2(1), 1-16. doi: 10.32872/cpe.v2i1.2781

Lee, E. E., Depp, C., Palmer, B. W., Glorioso, D., Daly, R., Liu, J., Tu, X. M., Kim, H.C., Tarr, P., Yamada, Y. \& Jeste, D.V. (2018). High prevalence and adverse health effects of loneliness in community-dwelling adults across the lifespan: role of wisdom as a protective factor. International Psychogeriatrics. 1-16. doi:10.1017/ S1041610218002120

Leão, A. M., Gomes, I. P., Ferreira, M. J. M., \& Cavalcanti, L. P. G. (2018). Prevalence and factors associated with depression and anxiety among university students in the field of Health in a large urban center in the Northeast of Brazil. Revista Brasileira de Educaşão Médica, 42(4), 55-65. doi: 10.1590/1981-52712015v42n4RB20180092

Lipp, M. E. N., \& Guevara, A. J. H. (1994). Validação empírica do Inventário de Sintomas de Stress. Estudos de Psicologia, 11(3), 43-49.

Lipp, M. E. N. (2000). Manual do Inventário de Sintomas de Stress para Adultos de Lipp (ISSL). São Paulo: Casa do Psicólogo.

Neto, F. (2014). Socio-Demographic predictors of loneliness across the adult life span in Portugal. Interpersona, 8(2), 222-230. doi:10.5964/ijpr.v8i2.171

Neto, J. M. S., Silva, S. S., \& Oliveira, M. S. (2017). Life style of physical education students. Educación Física y Ciencia 19(2), 1-11. doi: 10.24215/23142561e039

Oliveira, N. R., \& Barroso, S. M. (2020). Solidão, depressão e suporte social em estudantes de psicologia. Revista Trabalho En(Cena), 5(1), 146-162. doi: 10.20873/25261487V5N1P146

Psico-USF, Bragança Paulista, v. 26, n. 3, p. 559-570, jul./set. 2021 
Osório, F. L., Mendes, A. V., Crippa, J. A., \& Loureiro, S. R. (2009). Study of the discriminative validity of the PHQ-9 and PHQ-2 in a sample of Brazilian women in the context of primary health Care. Perspectives in Psychiatric Care, 45(3), 216-227. doi: 10.1111/j.1744-6163.2009.00224.x.

Pellegrini, C. F. S., Calais, S. L., \& Salgado, M. H. (2012). Social skills and time management on stress handling. Arquivos Brasileiros de Psicologia, 64 (3),110-129.

Pinho, R. (2016). Characterization of the clientele of a psychological treatment program for university students. Psicología, Conocimiento y Sociedad, 6(1), 114-130.

Russell, D., Peplau, L. A., \& Ferguson, M. L. (1978). Developing a measure of loneliness. Journal of Personality Assessment, 42(3), 290-294. doi: 10.1207/ s15327752jpa4203_11

Russell, D., Peplau, L. A., \& Cutrona, C. E. (1980). The revised UCLA Loneliness Scale: concurrent and discriminant validity evidence. Journal of Personality and Social Psychology, 39(3), 472-480. doi: 10.1037/0022-3514.39.3.472

Santos, I., Tavares, B. F., Munhoz, T. N., Almeida, L. S. P., Silva, N. T. B., Tams, B. D., Patella, A. M., \& Matijasevich, A. (2013). Sensitivity and specificity of the Patient Health Questionnaire-9 (PHQ-9) among adults from the general population. Cadernos de Saúde Pública, 29(8), 1533-1543. doi: 10.1590/0102-311X00144612

Segrin, C., McNelis, M., \& Pavlich, C. A. (2017). Indirect effects of loneliness on substance use through stress. Health Comunication. doi: 10.1080/10410236.2016.1278507
Serra, R. D., Dinato, S. L. M., \& Caseiro, M. M. (2015). Prevalence of depressive and anxiety symptoms in medical students in the city of Santos. Jornal Brasileiro de Psiquiatria, 64(3), 213-220. doi: 10.1590/0047-2085000000081

Stickley, A., \& Koyanagi, A. (2016). Loneliness, common mental disorders and suicidal behavior: Findings from a general population survey. Journal of Affective Disorders, 197, 81-87. doi: 10.1016/j. jad.2016.02.054

Stoliker, B. E., \& Lafreniere, K. D. (2015). The influence of perceived stress, loneliness and learning burnout on university student's educational experience. College Student Journal, 49(1), 146-160.

Victor, C. R., \& Yang, K. (2012). The prevalence of loneliness among adults: a case study of the United Kingdom. The Journal of Psychology: Interdisciplinary and Applied, 146(1-2), 85-104. doi: 10.1080/00223980.2011.613875

Vignola, R. C. B., \& Tucci, A. M. (2014). Adaptation and validation of the depression, anxiety and stress scale (DASS) to Brazilian Portuguese. Journal of Affective Disorders, 155, 104-109. doi: 10.1016/j. jad.2013.10.031

Zhang, S., Tian, Y., Sui, Y., Zhang, D., Shi, J., Wang, P., Meng, W., \& Si, Y. (2018). Relationships between social support, loneliness, and internet addiction in Chinese postsecondary students: a longitudinal sross-lagged analysis. Frontiers in Psychology, 9, 1-13. doi: 10.3389/fpsyg.2018.01707

Recebido em: 03/09/2019

Reformulado em: 06/07/2020

Aprovado em: 01/09/2020 
About the authors:

Sabrina Martins Barroso - Bachelor degree in Psychology from Federal University of São João del-Rei (UFSJ). Specialist in Human Development. Master's degree in Psychology and Doctorate degree in Public Health (Epidemiology) from Federal University of Minas Gerais (UFMG). Professor at Federal University of Triângulo Mineiro (UFTM). ORCID: https://orcid.org/0000-0003-1759-9681

E-mail:smb.uftm@gmail.com

Heloísa Gonçalves Ferreira - Psychologist, Master's and Doctorate degree in Psychology from Federal University of São Carlos (UFSCar). Specialist in Behavior Therapy. Professor at the Department of Cognition and Development - Institute of Psychology- University of Rio de Janeiro State - UERJ.

ORCID: https://orcid.org/0000-0002-3545-9378

E-mail: helogf@gmail.com

Contact:

Rua Vigário Carlos, 100, sala 525, Bairro Abadia

Uberaba-MG, Brazil

CEP: 38025-350 